\title{
A Framework for Mobile Education System for Higher Institutions in Nigeria
}

\author{
Boukari Souley1, David Emmanuel Aniobi2 \\ ${ }^{1}$ Department of Mathematical Sciences, Abubakar Tafawa Balewa University (ATBU), Bauchi, Nigeria \\ ${ }^{2}$ Department of Mathematics, Statistics and Computer Science, University of Agriculture Makurdi (UAM), \\ Makurdi, Nigeria \\ Email: bsouley2001@yahoo.com, david.aniobi@googlemail.com
}

Received 24 June 2014; revised 20 July 2014; accepted 15 August 2014

Copyright (C) 2014 by authors and Scientific Research Publishing Inc.

This work is licensed under the Creative Commons Attribution International License (CC BY). http://creativecommons.org/licenses/by/4.0/

(c) (i) Open Access

\begin{abstract}
With the advent of cloud computing technology, the development of mobile applications for use in several facets of life has been on the increase. This has been supported by the proliferation of mobile devices in the society which is also being used in utilizing the prowess of the cloud technology. Building a mobile education system that is platform independent is a major challenge since most of the popularly used ones are either software dependent or hardware dependent. In this work, a framework for mobile education system that is cross platform in nature with regard to operating system, hardware and web browsers using the 3-tier Client/Server mobile application architecture built on web standard was developed and fully tested. A first year computer science course offered by more than 1000 students was used as input to validate the framework. An integration of Short Message Services (SMS), virtual classroom and e-assessment components enable students and lecturers to communicate, create discussion forum and carry out e-testing using their mobile devices. This work is strongly recommended for higher institutions in Nigeria that need to explore the use of mobile devices that are available with the majority of students. Only registered users can access the developed app via the use of handheld devices (smart-phones \& tablets). This can actually improve learning, research and collaboration between students and lecturers thereby enhancing learning experience.
\end{abstract}

\section{Keywords}

Cloud Computing, e-Learning, Distance Education, e-Assessment, Mobile Devices

\section{Introduction}

Globalization created opportunities and challenges for learners in higher education to emphasis on Information 
and Communication Technologies (ICTs) such as Internet usages [1]. As it is today, no education system can thrive without having to directly or indirectly socket itself to the huge amount of knowledge made available on the web.

In [2], education is viewed as the process of teaching, training, and learning in schools and colleges for the development of knowledge and skills so as to prepare individuals to live happily with themselves and others in the society where they live. The fast growing technologies have changed the ways of teaching and learning in educational institutions since late the 1990s. This integration between technologies and educational environment has facilitated the communication between students and teachers, but at the same time raises new challenges as well [3].

Cloud computing, which has to do with the use of computing resources (hardware and software) that are delivered as a service over a network (typically the Internet), there has been dramatic increase in the development of Internet applications daily for academic and non-academic purposes so as to utilise the proficiency of the cloud technology. Cloud computing could also be seen as a general term for anything that involves delivering hosted services over the Internet.

The proliferations of wireless networks and small portable computing devices have led to the emergence of the mobile computing paradigm with which the cloud computing technology provides the platform for their operation. Mobile and Nomadic users carrying laptops or hand-held computers are able to connect to the Internet through publicly available wire line or wireless networks [4].

Mobile application commonly called mobile app is a software application designed to run on Smart phones, tablet computers and other mobile devices.

The popularity of mobile applications has continued to rise, as their usage has become increasingly prevalent across mobile phone users. A May 2012 comScore study reported that during the previous quarter, more mobile subscribers used apps than browsed the web on their devices: $51.1 \%$ vs. $49.8 \%$ respectively [5].

In [6], it was observed that Mobile applications come in two basic flavors: native applications, which are compiled programs that run natively on the device, and mobile web applications, which run inside a web browser on the device. Native applications are fast, have access to all of the power of the platform they are built for, and so forth. However, they suffer from one important limitation: they are not portable. If you want to make your application available on multiple platforms, you either have to write it in multiple languages (resulting in multiple code bases to maintain) or use a platform abstraction layer like Titanium or PhoneGap.

Mobile web applications, on the other hand, are created in HTML, CSS, and JavaScript, and run in the web browser on the mobile device. This means one code base to maintain; but mobile web applications still need to account for variations in web browsers across platforms.

The objective of this paper is to design a framework and develop a mobile application platform for education in higher institutions in Nigeria. The Mobile Application Framework for Higher Institution of learning (MAFHIL) developed will be capable of registering new students and their courses, give students access to course materials which are downloadable, allow students participate in virtual course-room discussion and e-assessment of students amongst others; consequently providing a platform for learning via the use of mobile devices.

\section{Related Work}

\subsection{Distance Learning}

Traditionally distance learning has been used to provide educational opportunities for the group of students for whom the usual educational system is not suitable. For example the people who work in different places, studying at home, living in isolated places or people with physical disorder [7]. Distance learning is a procedure of remote learning where teachers and students are far from each other. Students can study by themselves without physically meeting in the classroom; they don't need to go to schools or universities. With distance learning instruction, teaching and learning can take place even though the teacher and learner are physically separated during the process.

According to [8], distance learning programs and courses, mainly web-based, have entered the mainstream of higher education. Distance learning commenced in the twenty century and in this learning system everyone in the world in anywhere has opportunities to study autonomously. The use of the multimedia computer network becomes the leading technology of communication, observing a gradual breakdown of traditional barriers in the 
domain of learning [9]. The more recent distance learning systems are using the hybrid approach by linking different technologies (e-mail, conferencing, Computer Aided Instruction (CAI) material, video link, audio graphics, phone, fax) to provide comprehensive support, with each task matched to an appropriate medium for delivery and fulfilment [10].

\section{2. e-Learning}

e-learning technologies delivered online courses, seminars, discussion forums and other approaches for an innovative way of learning to interact with instructors and other students. In addition, e-learning is viewed as an innovative method for delivering education electronically and interactive learning environments for anyone, from anyplace and anytime by utilizing the Internet and digital technologies. e-learning also involves the use of ICT infrastructures ([11] [12]).

According to [13], e-learning is an educational system for providing learning through electronic technologies especially the Internet. e-learning brings a community of learners together and unrestricted by the time and place where students are able to discuss with other fellows and teachers via online and gather different types of knowledge from the different discussion forums. e-learning is a relatively new phenomenon and is defined as delivering education to students who are not physically present [14]. Rather than being in lecture halls in person, students and teachers can communicate with each other using the Internet. e-learning could be either synchronous or asynchronous or even both.

- Synchronous e-learning: This is when teachers and students communicate in real time by using webcams and microphones for instance. The communication is done live and thus it leaves some room for interaction in the form of students asking questions and getting answers to their questions shortly after. It is interesting to note that since synchronous e-learning is done in real time, it requires a relatively fast Internet connection, something that was not available ten years ago.

- Asynchronous e-learning: This on the other hand is when students can download or stream pre-recorded materials (lectures or written documents for instance). Asynchronous e-learning has its limitations when it comes to interaction between teacher and student [15].

However, it possess a great advantage in that it offers students more flexibility as students can download lectures and watch them at any point they wish [16]. Communication is also necessary for learning improvement to be an interaction of sharing or exchanging information with each other in learning-teaching process [17].

For synchronous as well as asynchronous e-learning, the platform that is generally used is an intranet-where lectures and documents can be uploaded and made accessible for everyone within the intranet. However, due to technological development in recent years, new platforms for online learning have been made available.

\subsection{Learning Management System (LMS)}

In an educational context, e-learning platforms are also known as Learning Management Systems (LMSs) which are Internet based software. LMSs allow instructors to manage materials distribution, assignments, communications and other aspects of instructions for their courses [18]. Today, LMSs have become an integral component of the educational systems in most universities and interest is increasing in hybrid approaches that blend in class and online activities as stated in [3]. A LMS is not intended to replace the traditional classroom setting, but its main role is to supplement the traditional lecture with course content that can be accessed from campus or the Internet [19].

The most popular LMS are Modular Object-Oriented Dynamic Learning Environment (MOODLE), Online Learning and Training (OLAT), Claroline, eFront, Blackboard, Share Point LMS [20].

\subsection{Cloud Computing}

Cloud computing is a model for enabling ubiquitous, convenient, on-demand network access to a shared pool of configurable computing resources (e.g. networks, servers, storage, applications, and services) that can be rapidly provisioned and released with minimal management effort. This cloud model is composed of five essential characteristics, three service models, and four deployment models. Cloud computing isn't so much a technology as it is the combination of many pre-existing technologies. These technologies have matured at different rates and in different contexts, and were not designed as a coherent whole; however, they have come together to create a technical ecosystem for cloud computing. 
There are five major essential characteristics of cloud computing which differs from one cloud computing researcher to another. The five major characteristics are: On-demand self-service, broad network access, resource pooling, rapid elasticity and measured service.

The cloud computing concept is also divided into three different service models also referred to as infrastructure models or services delivery models are generally categorized as Software as a Service (SaaS), Platform as a Service (PaaS) and cloud Infrastructure as a Service (IaaS). Cloud computing can also be divided on the basis of deployment, level of access, of the cloud services. The deployment models of cloud computing are Private cloud, Public cloud, Community cloud and Hybrid cloud ([21] [23]).

\subsection{Cloud Computing and Education}

The application of the Cloud computing technology in educational system has undoubtedly brought a great change in the academic square as it has revolutionalized learning by introducing new paradigm in the field of learning. The Cloud technology has made information sharing and accesses very easy on the universal platform. With the use of a local area network, multiple users can work on the same file; but it can be more interactive, and all encompassing as students from around the globe can participate in the same exercise there by not limited by geographical location.

With the Cloud, documents are not physically hosted on the user's computer; they can be retrieved from anywhere through an Internet connection. So, working in the cloud means that users don't need to depend on a particular program or even a specific operating system any more. The only requirement to start working in the cloud is a device with an Internet connection.

Students can share/access a document online, simultaneously interact and discuss with one another on academic issues and equally carryout their test exercises on scheduled date and time. These are part of the collaborative and communicative environments supported by the cloud which creates an adequate educational environment for Students and Lecturers, to improve teaching and learning processes in higher institutions of learning.

\section{Methodology}

\subsection{System Analysis and Modeling}

\section{Problems of the Existing Systems}

The existing learning management systems or applications for academic purposes in most schools in Nigeria where they exist (from analysis) are associated with the following problems or challenges:

* Difficulty in accessing the application via mobile devices.

* Lack of up-to-date course materials for instruction and learning.

* Difficulty in students submitting assignment online and some do not have the platform or such task.

* The existing system is not patronized by the students and Lecturers as it’s time demanding on them, because it requires them to get to a café before accessing the application.

* Most of the existing learning management systems do not have an e-testing platform.

* Lack of available online platform in most schools for instruction and learning for the students.

* Some of the existing mobile applications are difficult to customize as most of them are tailored towards a particular device or operating system.

\section{Functional Requirements}

Based on the problems of the existing system, the proposed system should be able to achieve the following functional requirements:

- Downloading of academic e-books and other instructional materials.

- Uploading and submissions of student assignments.

- Serving as a platform for learning and information dissemination via short message service to students using their mobile phone numbers; and also use for advertisement purpose.

- Providing a platform for access control so that only registered students can have access to portal.

- Enabling the conduct of e-test (e-assessment) using the multiple choice question kind of testing and essay type.

- Creating a virtual course room via the Internet which facilitates communication among the participants by allowing students and Lecturer to meet virtually in forum discussion (asynchronically) in Chat. Each post in the forum is identified by its title or reference tag. 


\subsection{Use Case Modeling}

Unified Modelling Language (UML) can be seen as a modeling language that is used to model systems using object oriented concepts. A use case diagram is part of the UML set of diagrams and it describes externally the visible behavior of a system and provides a view of the users of the system and the functions that the system must perform; it shows the important actors and functionality of the system [23]. The major actors in the proposed system are administrator, lecturers and students. The use case diagram for the proposed system is shown in Figure 1 which indicates all the tasks carried out by each of them.

\section{- System Model/Architecture}

The mobile application architecture considered for this work is the 3-tier Client/Server architecture for web app built on a cross-platform standard using the web, shown in Figure 2.

At the presentation services tier, Mobile/Handheld devices will be used by the user to access the application via a web browser. It's at this layer that all information gathering from the user is done and sent to the business services for processing, results of all the business services processing are also received back.

The business services tier serves as the web server where all form of processing is done as inputs are received from the presentation layer. It also Interacts with the data services to perform the business operations and processed results is sent to the presentation tier. At the data services tier the application data is stored, retrieval and maintenance operations are carried out on the data, and integrity of data is also maintained.

\section{- Proposed System Framework}

The mobile app developed is cross platform in nature with regards to operating system, hardware (i.e. handheld devices) and web browsers.

With regard to browsers the application will be no specific browser dependent, as it will allow the contents to be displayed/rendered in any browsers without the loss of originality. The mobile application framework adapted in this paper is shown in Figure 3.

With the app deployed on the Cloud; every wireless client accessed the app in the Cloud from their handheld devices through an Access point (which could be a GSM network, Wireless Fidelity (WiFi), etc.).

The likely complexities that should be the focal point and has to be focused on at the course of building this framework are as follows:

- The use of development technologies (programming tools) that is not device dependent, web browser and operating system dependent.

- It should include most if not all learning activities obtainable at the traditional archetype of learning.

\section{System Design}

\section{- Output Interface Design}

The output generated from a system determines the reliability of the system. Output design refers to the format of the value to be generated or expected from the system. Figure 4 illustrates a sample output interface of the proposed system.

\section{- Input Interface Design}

The Input design indicates the specification of the input data that the system requests from the user. Figure 5 shows a sample input interface for the system.

\section{- File Design}

Relational database was used to keep the proposed system's importunate data. Figure 6 shows the graphical description of data entities in the database and the relationship that exists between them.

\section{- Program Architecture}

The program architecture of the proposed system is depicted in this work using a class diagram. A class as a set of objects that share common attributes and behaviour. The purpose of a class diagram is to depict the classes within a model [24]. Figure 7 is the class diagram framework for the proposed system.

\section{Testing and Results}

\section{* Testing}

The application prototype was developed using PHP, jQuery Mobile, HTML5 web development tools, with the help of NetBeans 7.1 as the PHP code Editor that support the use of Cascading Style Sheet (CSS3). The system backend was developed using MySQL as the database, with XAMPP as the local host server via TCP/IP. A 


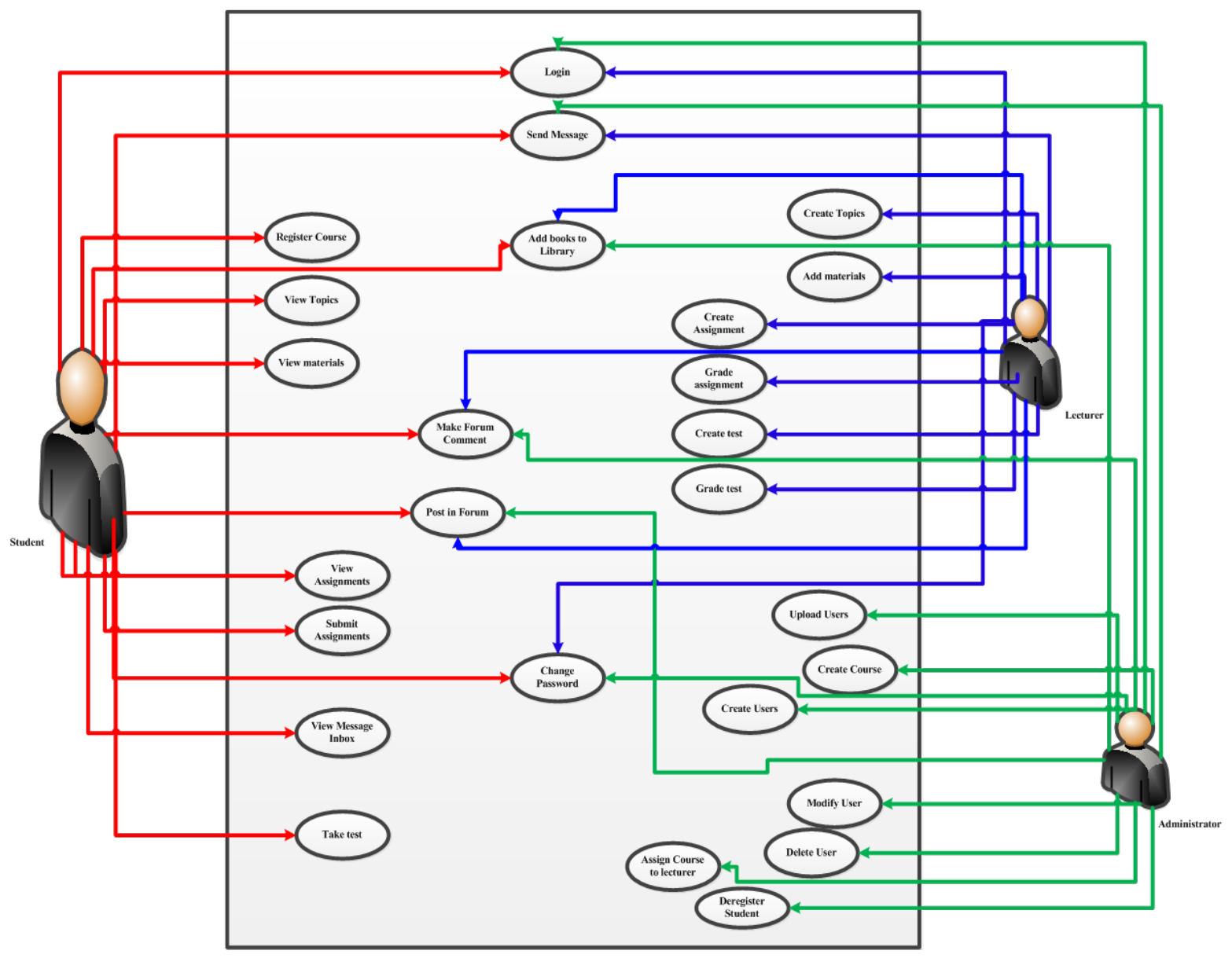

Figure 1. Proposed system use case diagram.

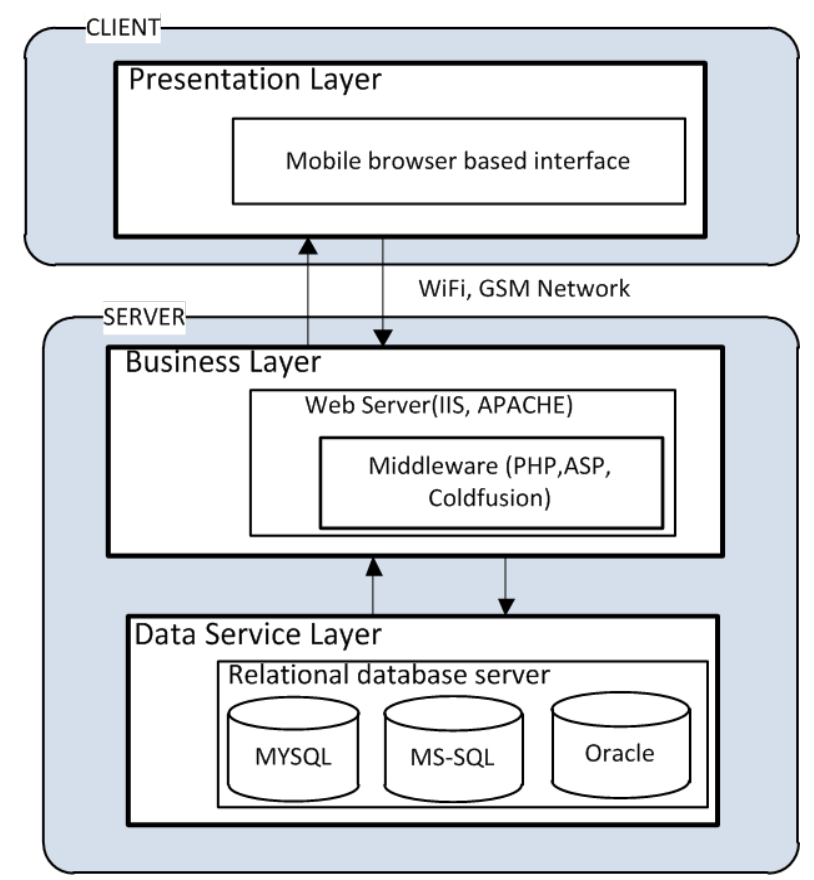

Figure 2. Main system architecture. 


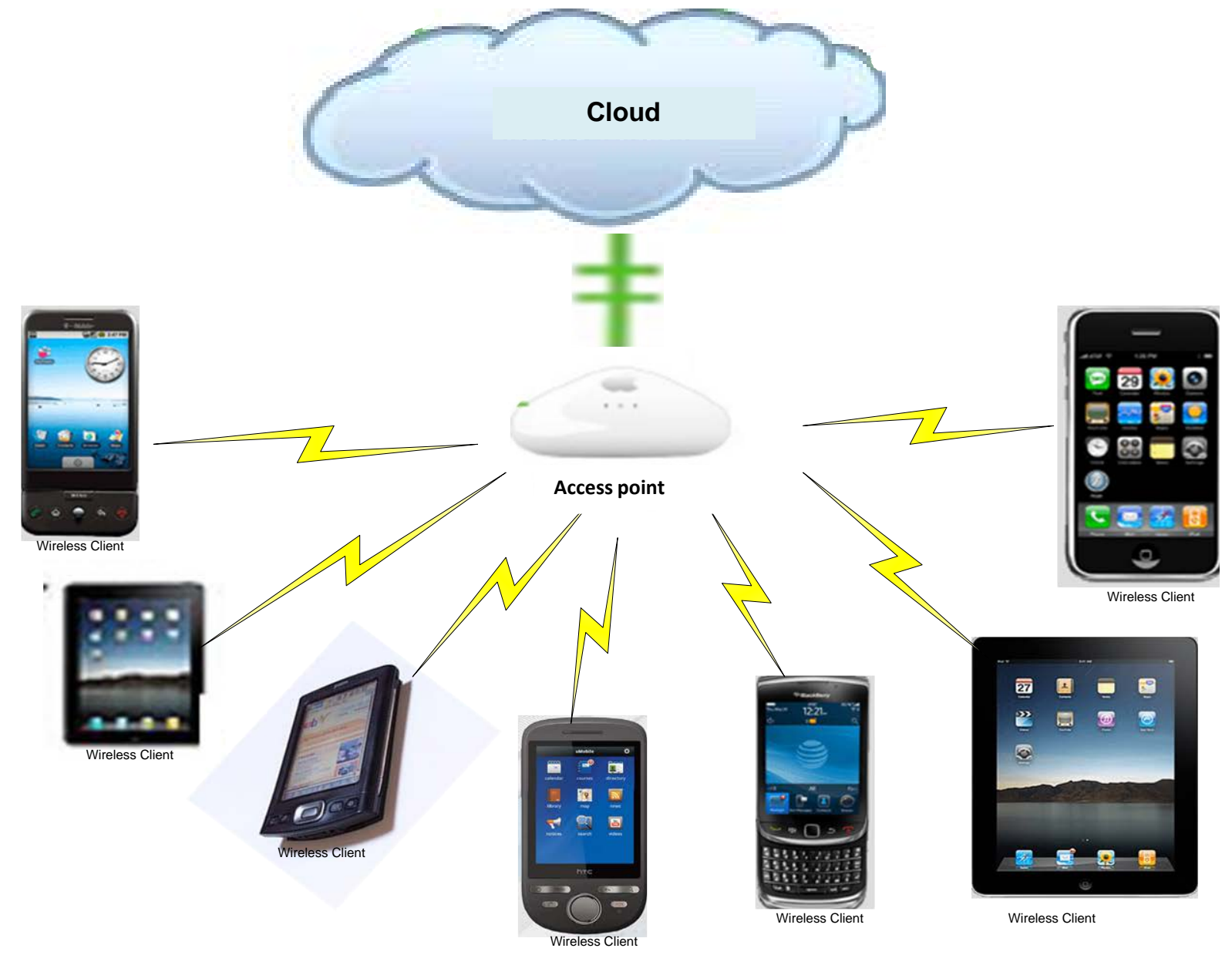

Figure 3. Cloud computing mobile application framework for learning.

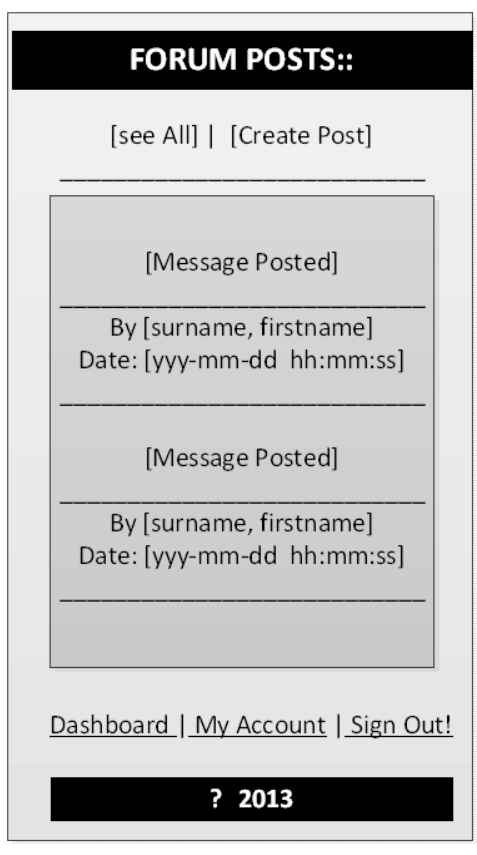

Figure 4. Output interface. 


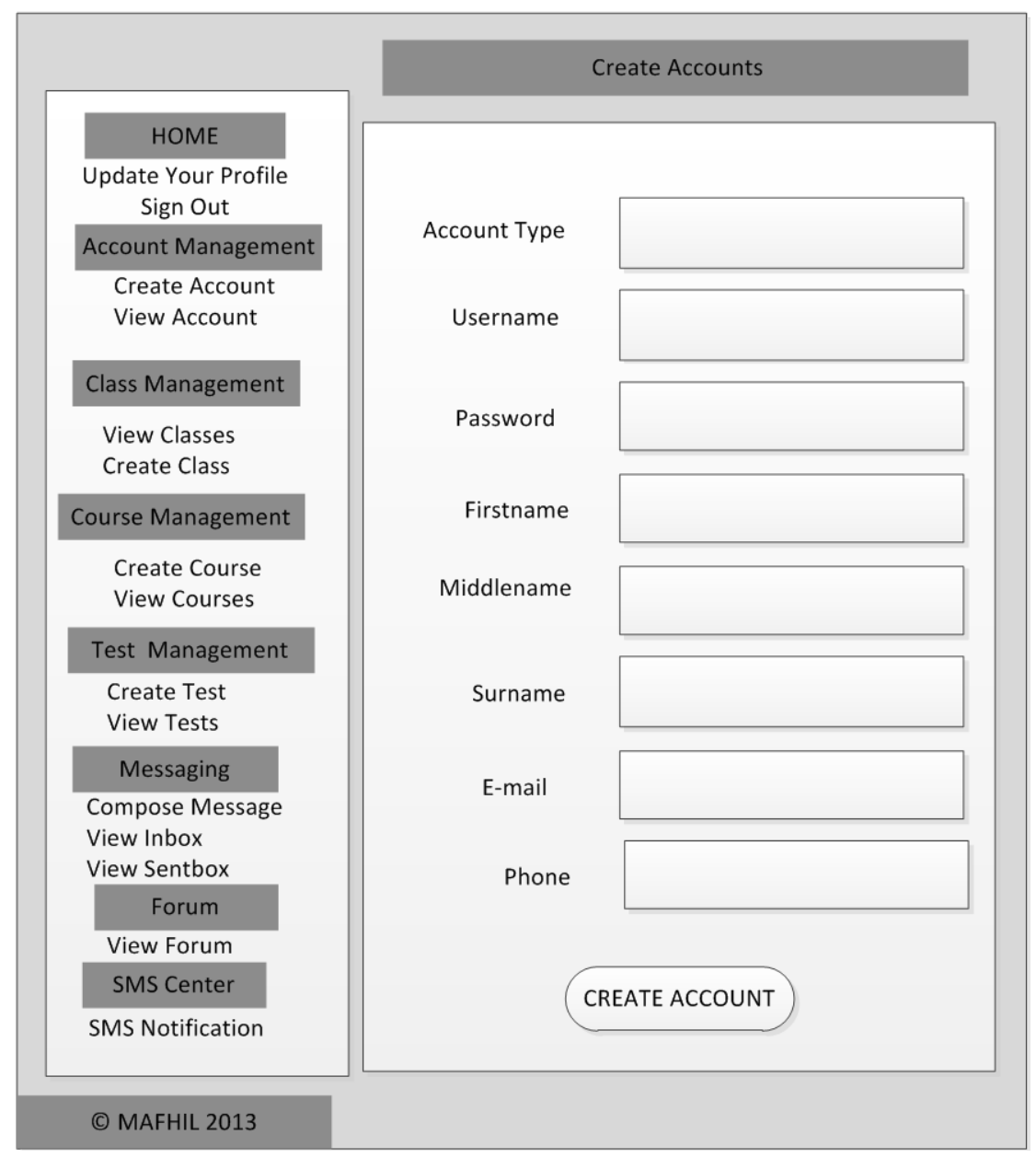

Figure 5. Input interface.

first year computer science offered by a larger number of students from different departments was used as input.

The system prototype was deployed on the Cloud and the application was duly tested for hardware compatibility, software compatibility (i.e. with regards to device operating system and mobile web browsers) and usability as specified in the functional requirement of the system.

Figures 8-19 give a vivid representation of the different test cases and some sample test data used.

Other test cases are: Test case 12: hardware compatibility, test case 13: Operating System compatibility and test case 14: Web browser compatibility.

- Results

The result of the different tests carried out on the system is shown in Table 1.

\section{- Discussion of Results}

When the application was deployed on to the Cloud, the entire system was meticulously tested with the required test cases supplied at different stages and on different platforms in order to ascertain that the system meets its set objectives. Invariable and valid results were obtained from the test which showed that the system is working as expected and that it's cross-platform in nature.

Table 2 shows the vital remarks on the exact result obtain from the testing carried out on the developed application prototype.

\section{Conclusion}

This work provided a framework for mobile education/learning system using the Cloud computing technology. The developed mobile web application prototype can be accessed mainly via handheld devices and can be seen 


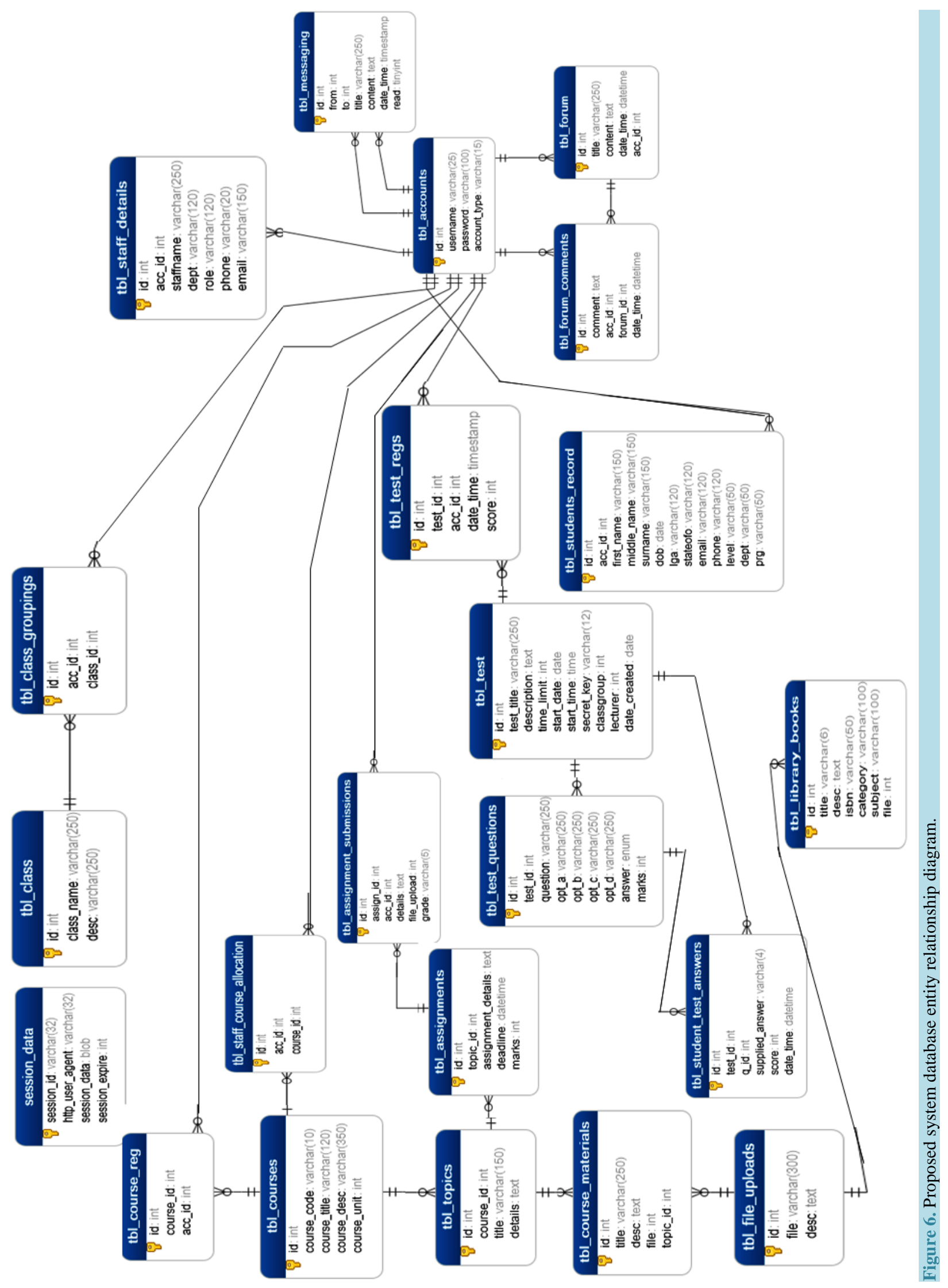




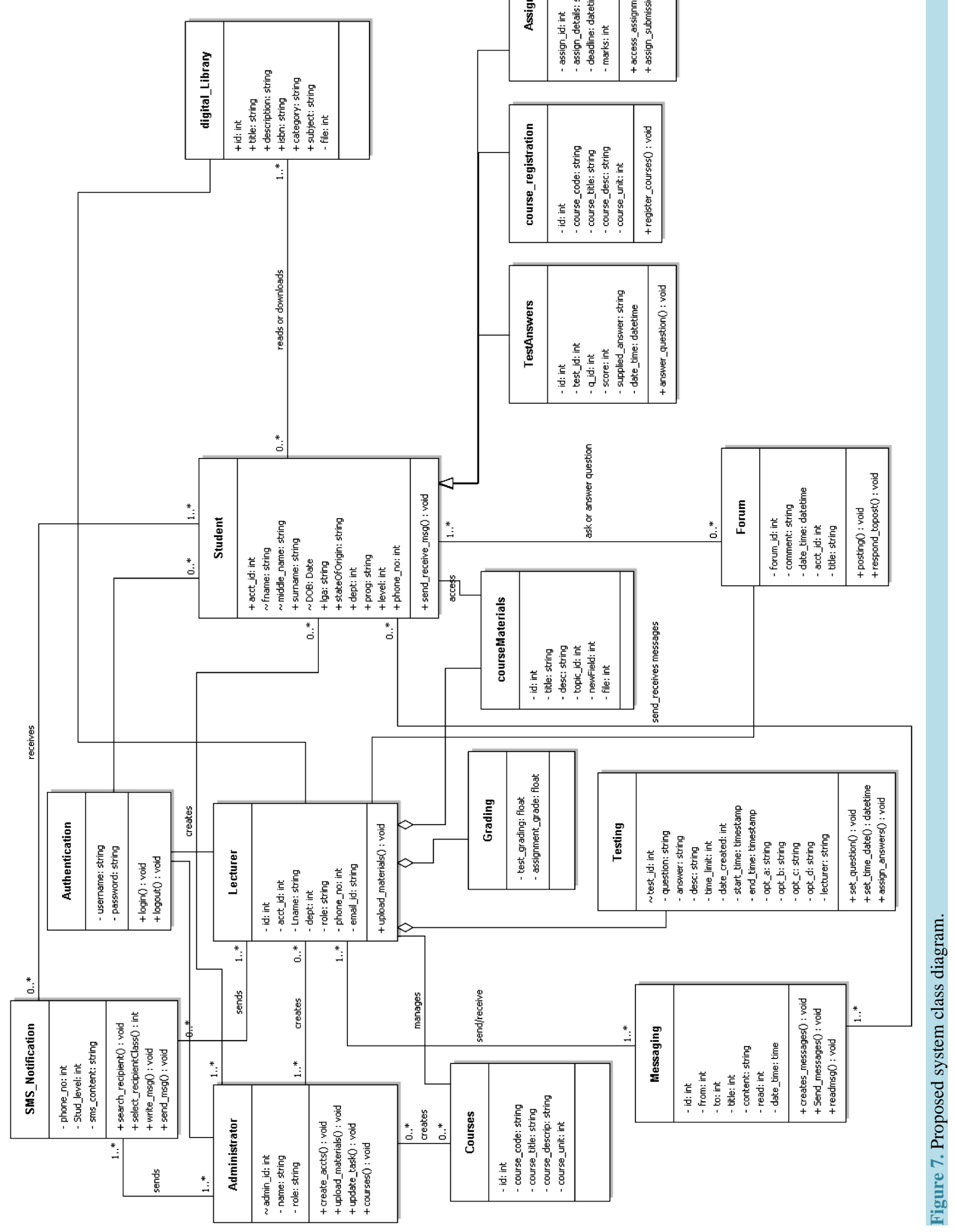




\section{Welcome to...}

You are welcome to MAFHIL Academic Solution

Please Login...

User ID.

$12 / 12347 / 1$

Password

*oklok

Login!

Figure 8. Test case 1 authentication.

\section{MAFHIL}

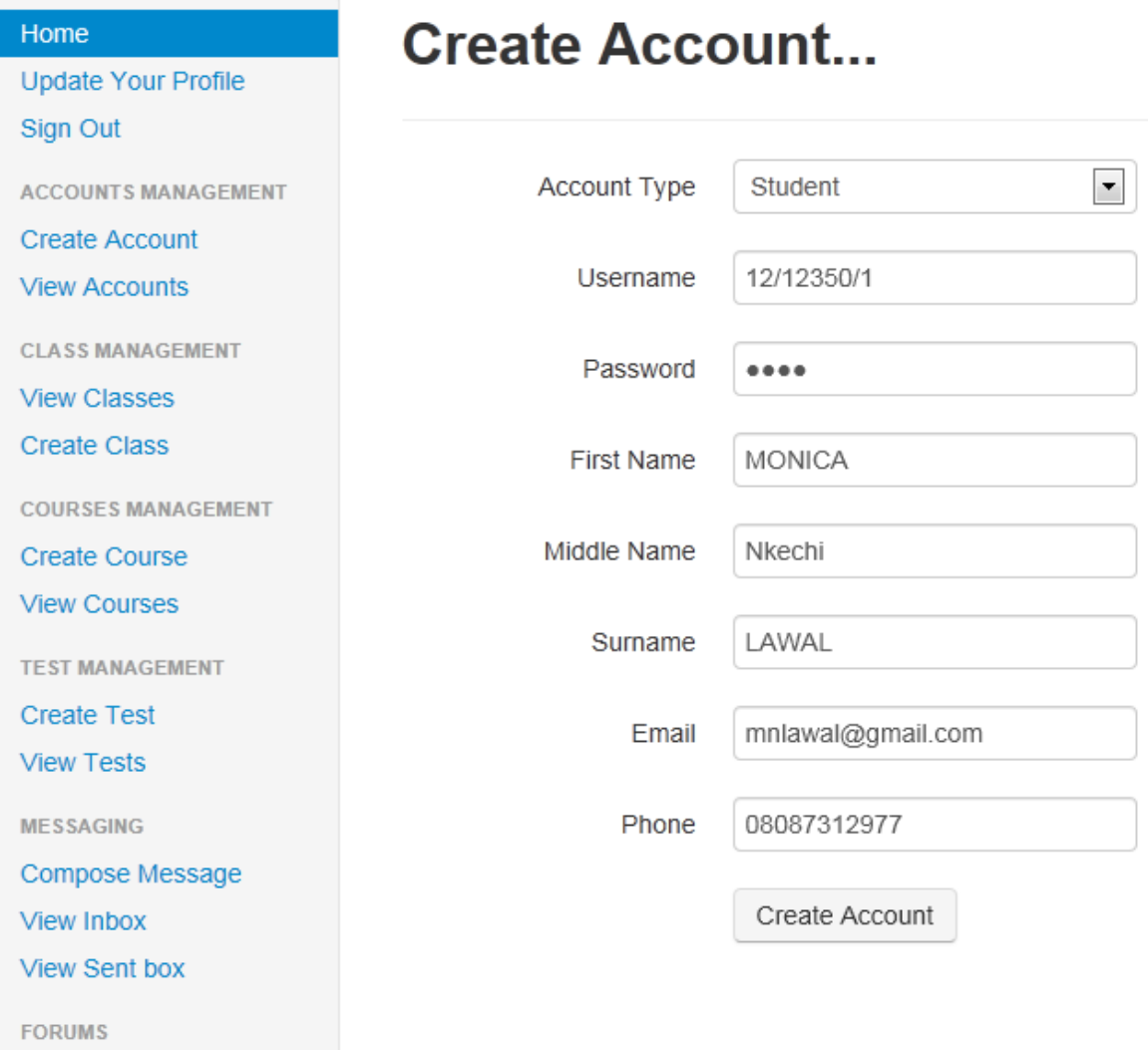

Figure 9. Test case 2 create account. 


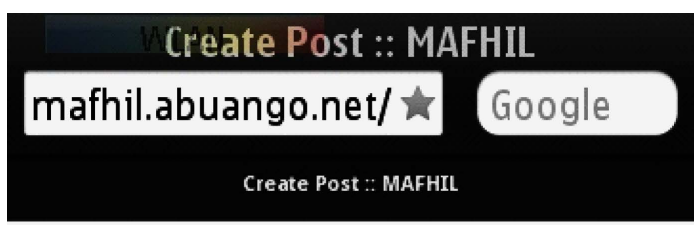

[ See All ] | [ Create Post ]

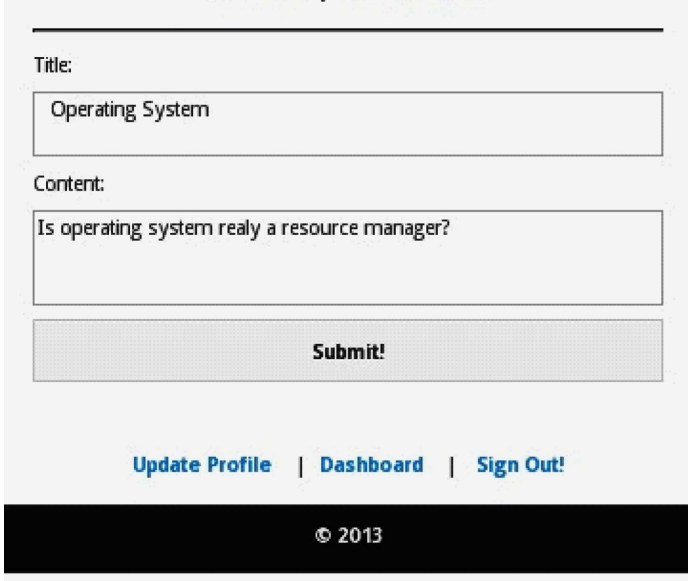

Figure 10. Test case 3 create post.

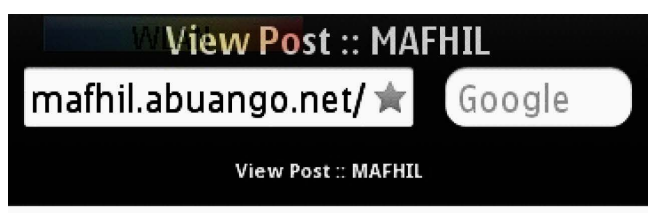

[ See All ] ] [ Create Post ]

\begin{tabular}{l}
\hline ASUU STRIKE VS FG \\
\hline By Abu Ango \\
Date: 2013-08-13 10:02:24 \\
\hline this strike is becoming longer than expected \\
\hline None Yetl \\
\hline Comment: \\
\hline bederal government should meet ASUU demand, bcus the nation is \\
\hline Update Profile I Dashboard । Sign Out! \\
\hline
\end{tabular}

Figure 11. Test case 4 comment on post. 


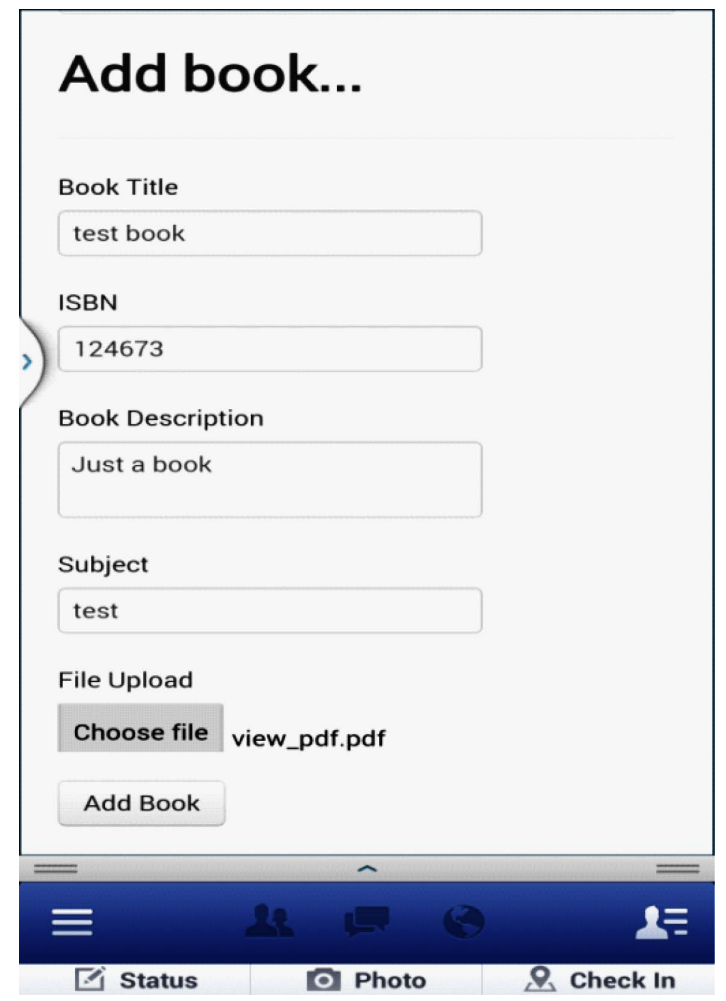

Figure 12. Test case 5 course material upload.

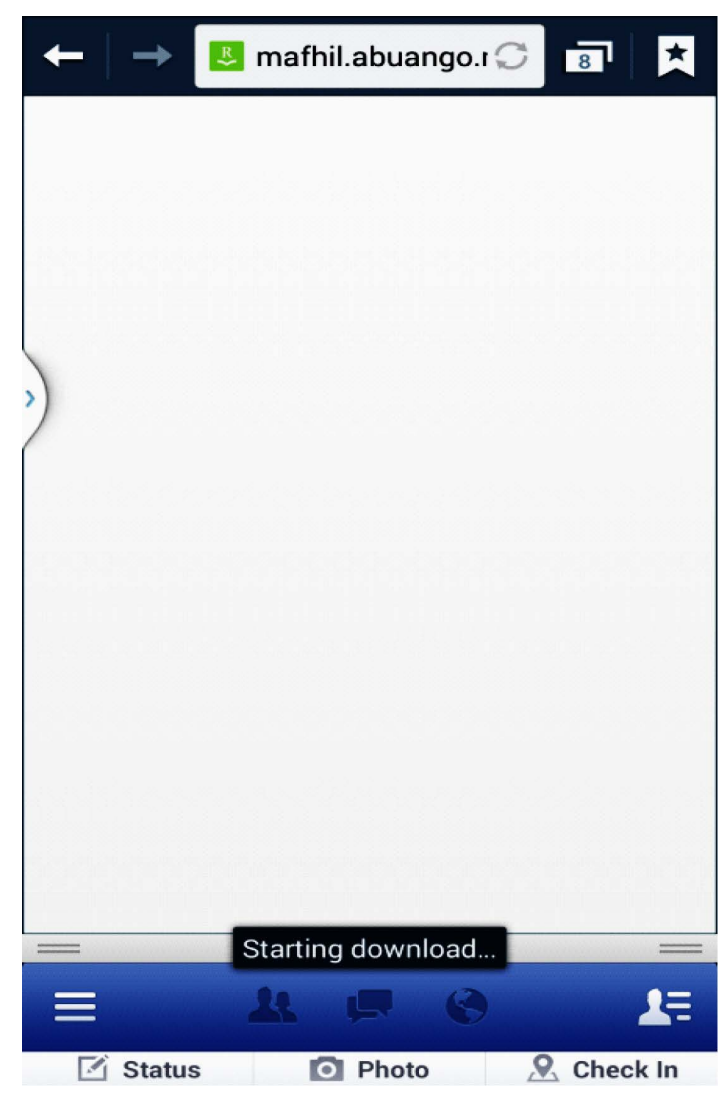

Figure 13. Test case 6 course material download. 


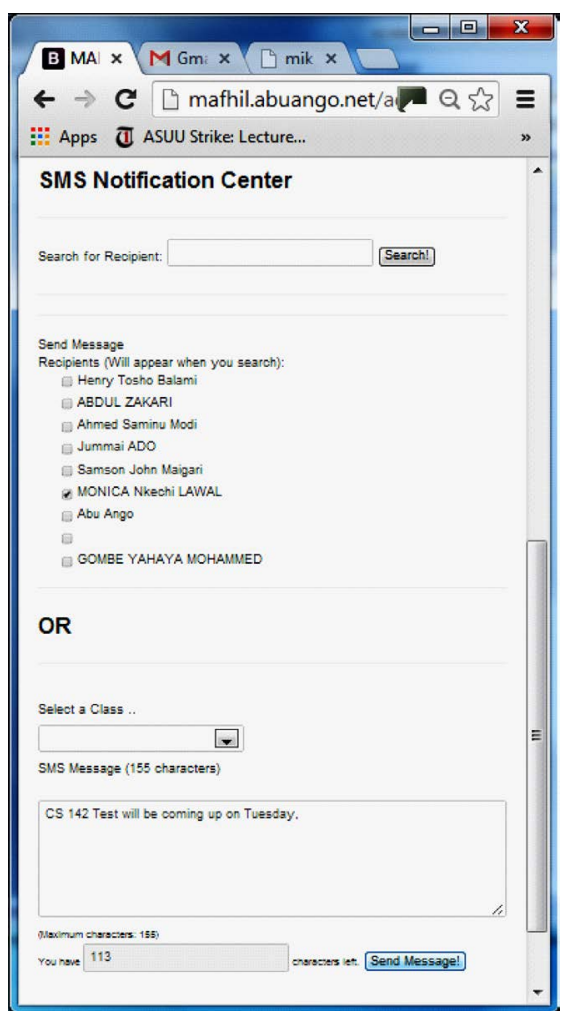

Figure 14. Test case 7 SMS notification.

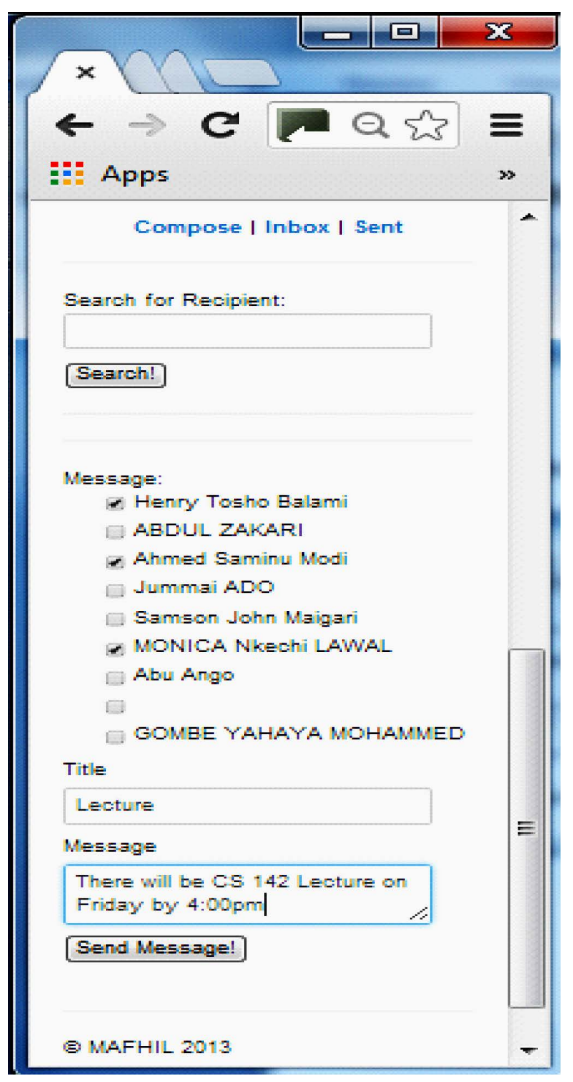

Figure 15. Test case 8 messaging. 
$\leftarrow \rightarrow \mathbf{C}[\square$ mafhil.abuango.net/admin/testfuncs.php?action=create

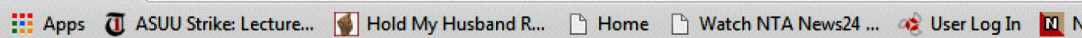

MAFHIL

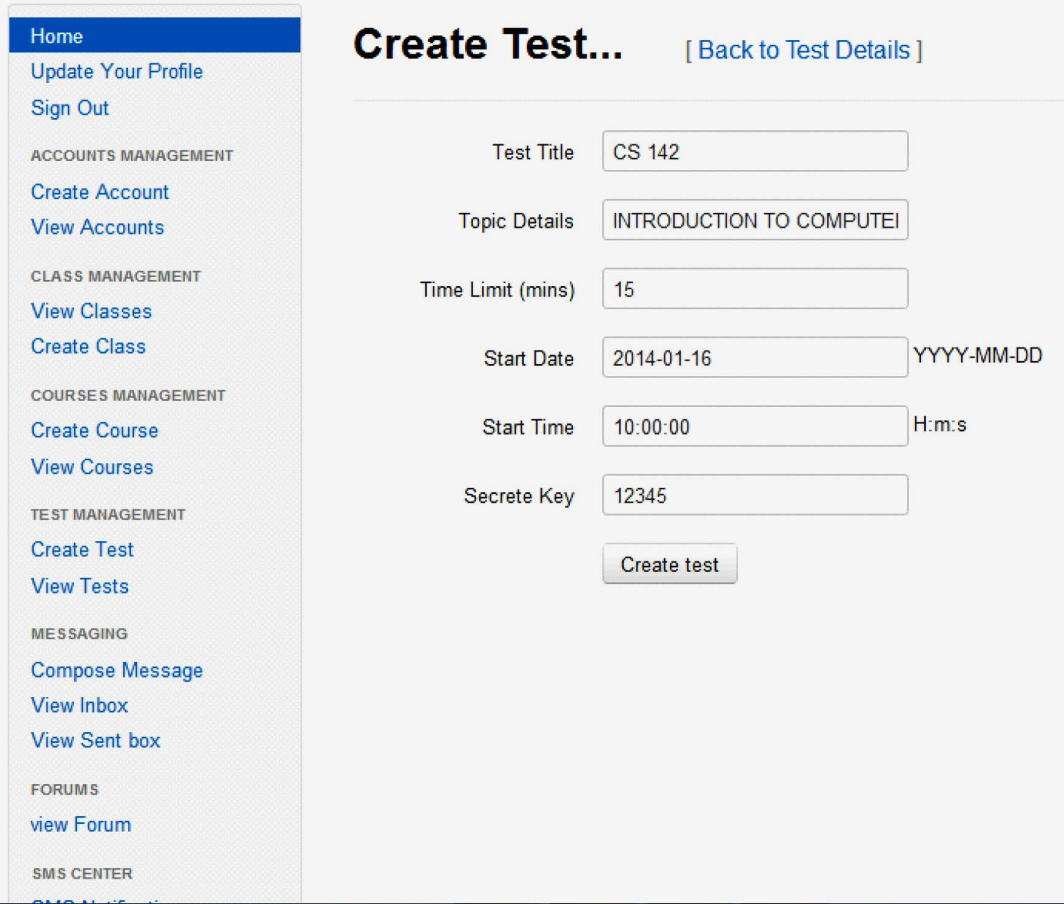

Figure 16. Test case 9 test creation.

$\leftarrow \rightarrow \mathbf{C} \square$ mafhil.abuango.net/admin/testfuncs.php?action=createQ\&t_id=11

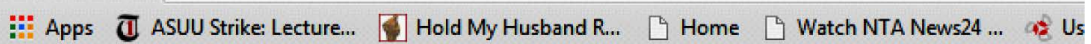

MAFHIL

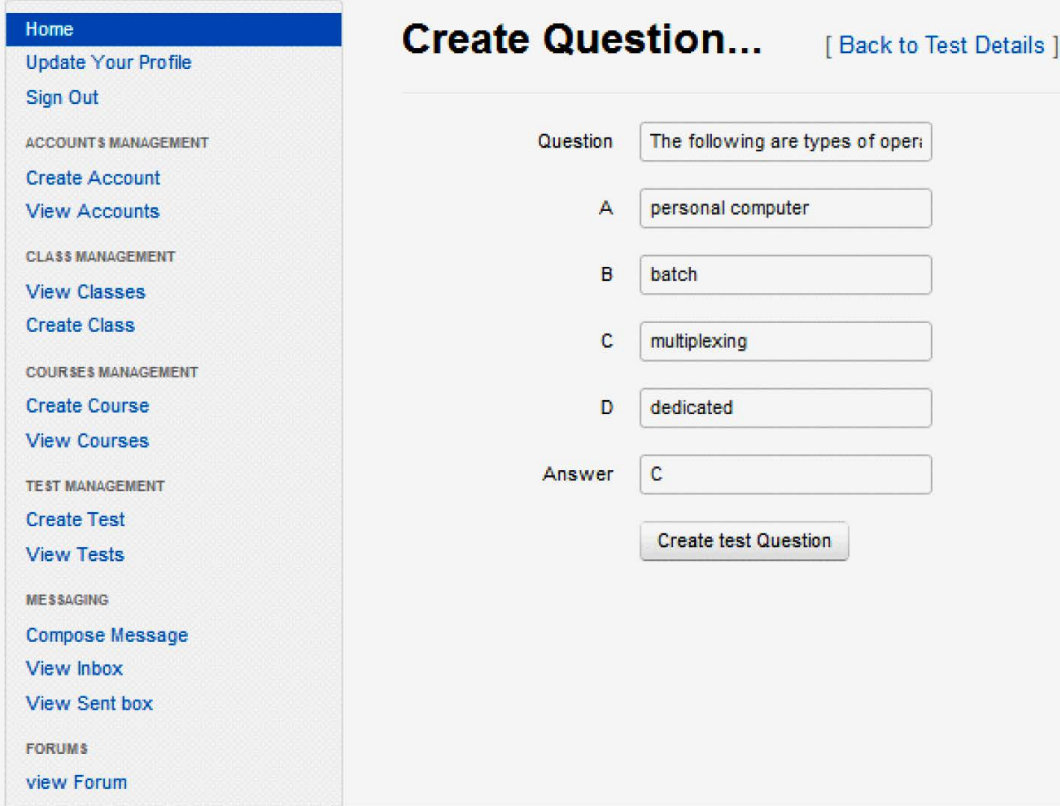

Figure 17. Setting test question. 


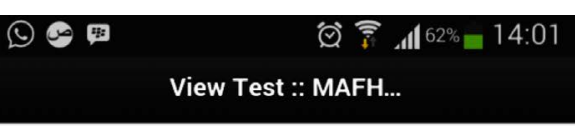

Test: CS 142

Test Starts: 2014-01-16, 14:00:00
Duration: 15 mins
Lecturer: ANIOBI DAVID EMMANUEL
Test Score: 0
Instruction: Do not spend beyond the required
duration, else you test will become invalid!
Take Test
Update Profile I Dashboard | Sign Out!
@ 2014

Figure 18. e-testing exercise step 1.

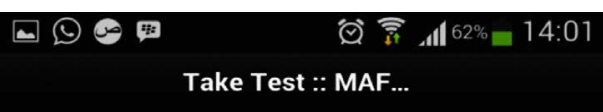

\section{Test: CS 142}

You started : 14:01:12

You must finish on/before : 14:16:12

Select one option for each question.

>)

1: The followings are process scheduling queues except

\section{Job queue}

2: How many transitions are found in the five state model of a process

\section{5}

3: JoyStick is an example of device.

$$
\text { output }
$$

4: All of these are types of Read Only Memory (ROM) except.

\section{PROM}

Figure 19. e-testing exercise step 2. 
Table 1. Result of system testing.

\begin{tabular}{|c|c|c|c|c|}
\hline Test case & System testing type & Testing objectives & Result & References \\
\hline Test case $1 \mathrm{a}$ & & Valid user authentication & Passed & Appendix (Figure 1A(a)) \\
\hline Test case $1 \mathrm{~b}$ & & Invalid user authentication & failed & Appendix (Figure 1A(b)) \\
\hline Test case 2 & & To test for user account creation & Passed & Appendix (Figure 2A) \\
\hline Test case 3 & & To test "Post" creation in forum & Passed & Appendix (Figure 5A) \\
\hline Test case 4 & & To test users commenting on post & passed & Appendix (Figure 4A) \\
\hline Test case 5 & & To test for course material upload & passed & Appendix (Figure 6A) \\
\hline Test case 6 & Usability & To test for course material download & passed & Appendix (Figure 7A) \\
\hline Test case 7 & & $\begin{array}{l}\text { To test for sending SMS notification } \\
\text { to lecturers \& students }\end{array}$ & passed & Appendix (Figure 8A) \\
\hline Test case 8 & & To test for messaging amongst users & passed & Appendix (Figure 9A \& Figure 10A) \\
\hline Test case 9 & & To test for “Test” creation & passed & Appendix (Figure 11A) \\
\hline Test case 10 & & To test for setting e-test questions & passed & Appendix (Figure 12A) \\
\hline Test case 11 & & To test for answering e-test questions & passed & Appendix (Figure 13A) \\
\hline Test case 12 & Hardware & To test for hardware compatibility & Passed & Appendix (Figures 14A-16A) \\
\hline Test case 13 & Software & To test for operating system compatibility & passed & Appendix (Figures 14A-16A) \\
\hline Test case 14 & Software & To test for web browsers compatibility & passed & $\begin{array}{c}\text { Appendix (Figure 1A, Figure 3A \& } \\
\text { Figure 16A) }\end{array}$ \\
\hline
\end{tabular}

Table 2. Discussion on actual result of the system testing.

\begin{tabular}{|c|c|}
\hline System testing type & Discussions \\
\hline $\begin{array}{l}\text { Hardware (i.e. hardware } \\
\text { compatibility) }\end{array}$ & $\begin{array}{l}\text { The following handheld devices were used in testing the application: Samsung Galaxy S Duos phone, } \\
\text { Apple iPad, Tecno N7 smartphone, Nokia C7 Smartphone and Blackberry. } \\
\text { The result obtained showed that the application can run on handheld devices not limited to the above } \\
\text { mentioned, these therefore make the application hardware independent as it could run on any mobile } \\
\text { device that can access the Internet via a web browser. The application is hardware compatible. }\end{array}$ \\
\hline $\begin{array}{l}\text { Software (i.e. mobile } \\
\text { browser compatibility) }\end{array}$ & $\begin{array}{l}\text { The web application was available on a running web server. It was accessed from different handheld } \\
\text { devices with different mobile web browser for example Safari Mobile web, Opera Mini, Firefox, Next } \\
\text { browser, Dolphin and one browser. } \\
\text { The result obtained showed that the application can run on all mobile browsers as no inconsistencies were } \\
\text { noticed apart from the user interface being rendered slightly different amongst different web browsers. The } \\
\text { application is mobile browser compatible. }\end{array}$ \\
\hline $\begin{array}{l}\text { Software (i.e. operating } \\
\text { system compatibility) }\end{array}$ & $\begin{array}{l}\text { The application was tested on handheld devices running different operating systems. It was ran on } \\
\text { Samsung Galaxy S Duos phone running version } 4.0 .3 \text { of the Android operating system, an Apple iPad } \\
\text { using the iOS operating system, Nokia phone with Symbian operating system and Blackberry phone with } \\
\text { the Blackberry operating system. The application is operating system compatible. }\end{array}$ \\
\hline $\begin{array}{l}\text { Usability (i.e. meeting } \\
\text { the objective of the } \\
\text { system) }\end{array}$ & $\begin{array}{l}\text { The application was successfully loaded in the web browser and students were able to register courses } \\
\text { successfully, download materials, attempt tests, Forum discussion, messaging and other functionalities as } \\
\text { specified. Lecturers were able to upload course materials, set test question and send SMS notifications to } \\
\text { students. The testing was successfully done in record time. The results of test and Assignment uploaded } \\
\text { were saved in the database as specified in the architecture. }\end{array}$ \\
\hline
\end{tabular}

as a viable alternative to some existing applications. The advantages are the same as for any other web application where the user avoids the hassle of installing an application as it is with native applications and will always run the latest version, and it is believed that the differences between browser implementations are less compared to other environments in which an application would run, for example Android operating system specific environments. Implementing this framework in academic institutions in Nigeria will significantly transform and help in the activities carried out in both regular and distance learning programmes as it equally provides quicker means of communication and collaboration amongst participants and information dissemination from lecturers to students. 


\section{References}

[1] Macharia, J. and Nyakwende, E. (2011) Gender Differences in Internet Usage Intentions for Learning in Higher Education: An Empirical Study. Journal of Language, Technology \& Entrepreneurship in Africa, 3, 244-253.

[2] National Teachers' Institute. General Methods in Education (PDE103) Postgraduate Diploma in Education. 2-4.

[3] Pishva, D., Nishantha, G.G.D. and Dang, H.A. (2010) A Survey on How Blackboard is Assisting Educational Institutions around the World and the Future Trends. 12th International Conference on Advanced Communication Technology (ICACT), Phoenix Park, 7-10 February 2010, 1539-1543.

[4] Helal, A., Haskell, B., Carter, J.L., Brice, R., Woelk, D. and Rusinkiewicz, M. (2002) ANYTIME, ANYWHERE Computing: Mobile Computing Concepts and Technology. Kluwer Academic Publishers, New York, 19-50.

[5] Perez, S. (2012) comScore: In U.S. Mobile Market, Samsung, Android Top the Charts. Apps Overtake Web Browsing. http://techcrunch.com/2012/07/02/comscore-in-u-s-mobile-market-samsung-android-top-the-charts-apps-overtake-web -browsing/

[6] Reid, J. (2011) jQuery Mobile. O’Reilly Media, Inc., Sebastopol, iv.

[7] Watabe, K., Hamalainen, M. and Whinston, A.B. (1995) An Internet Based Collaborative Distance Learning System: Codiless. Computers \& Education, 24, 141-155. http://dx.doi.org/10.1016/0360-1315(95)00013-C

[8] Consortium, S. (2006) Growing by Degrees: Online Education in the United States, 2005 (Southern Edition). 1-32.

[9] Nyiri, J.C. (1997) Open and Distance Learning in an Historical Perspective. European Journal of Education, 32, 347357.

[10] Douglas, S. (1993) Digital Soup: The ABCs of Distance Learning. EDUCOM Review, 28, 22-30.

[11] Cristina, M.E. (2009) Elearning Technologies. Annals of Dunărea de Jos University. Fascicle I: Economics and Applied Informatics, 50-58.

[12] Awodele, O., Kuyoro, S.O., Adejumobi, A.K., Awe, O. and Makanju, O. (2011) Citadel e-Learning: A New Dimension to Learning System. World of Computer Science and Information Technology Journal, 1, 71-77.

[13] Friesen, N. (2009) Rethink e-Learning Research: Foundation Method and Practice. [e-Book] Peter Lang Education. http://books.google.co.uk/

[14] Holmberg, B. (2005) The Evolution, Principles and Practices of Distance Education. Open Learning, 21, $273-277$.

[15] Andersen A., Hristov, E. and Karimi, H. (2008) Second Life: New Opportunity for Higher Educational Institutions. Bachelor Thesis within Business Administration, Jönköping International Business School, Jönköping University, Jönköping, 17.

[16] Peters, O. (2001) Learning and Teaching in Distance Education-Analyses and Interpretations from an International Perspective. 2nd Edition, London, 4-25.

[17] Karadag, E. and Caliskan, N. (2009) Interaction and Communication in the Process of Education and Shared Common Area in the Classroom. College Student Journal, 43, 123-128.

[18] Abu, S.B. (2009) Learning Management System and Its Relationship with Knowledge Management. 4th International Conference on Intelligent Computing and Information Systems, Cairo, 19-22 March 2009, 3-5.

[19] Landry, B., Griffeth, R. and Hartman, S. (2006) Measuring Student Perceptions of Blackboard Using the Technology Acceptance Model. Decision Sciences Journal of Innovative Education, 4, 87-99. http://dx.doi.org/10.1111/j.1540-4609.2006.00103.x

[20] Faxen, T. (2011) Improving the Outcome of e-Learning Using New Technologies in LMS Systems and Establishing the Requirements for an LMS System in an Academic Environment. Master of Software Engineering and Management Thesis, University of Gothenburg Department of Applied Information Technology, Gothenburg, 22-27.

[21] Mather, T., Kumaraswamy, S. and Latif, S. (2009) Cloud Security and Privacy An Enterprise Perspective on Risks and Compliance. O’Reilly Media, Inc., Sebastopol, 10-12.

[22] Mell, P. and Grance, T. (2011) The NIST Definition of Cloud Computing Special Publication 800-145. Recommendations of the National Institute of Standards and Technology, US Department of Commerce, 1-3.

[23] Gustafson, D.A. (2002) Theory and Problems Software Engineering. The McGraw-Hill Companies, New York, 14-20.

[24] Greer, D. (2010) Software Engineering. Queens University Belfast, Belfast. 


\section{Appendix}

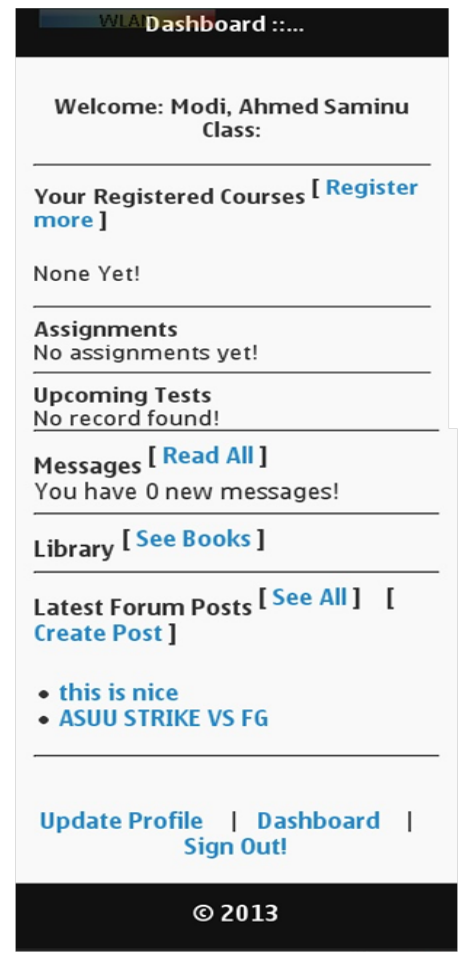

(a)

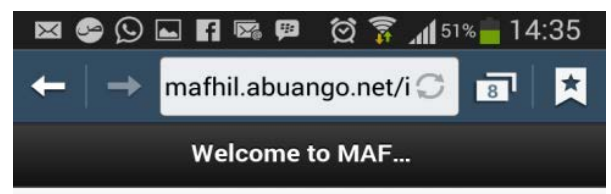

You are welcome to MAFHIL - Academic Solution

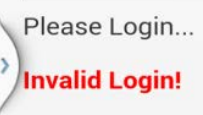

User ID.

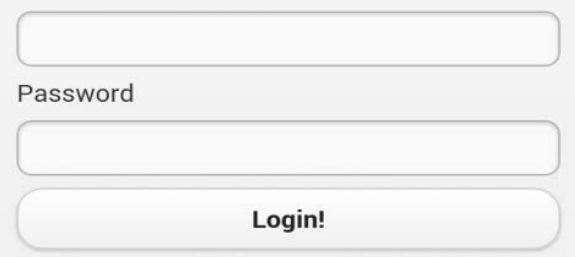

Update Profile | Dashboard | Sign Out!

(ㄷ) 2014

(b)

Figure 1A. (a) Students dashboard in NOKIA C7 with symbian OS and opera mini web browser; (b) Invalid User Login.

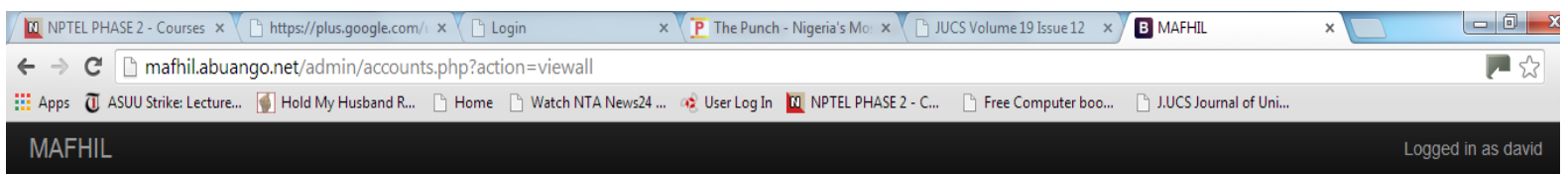

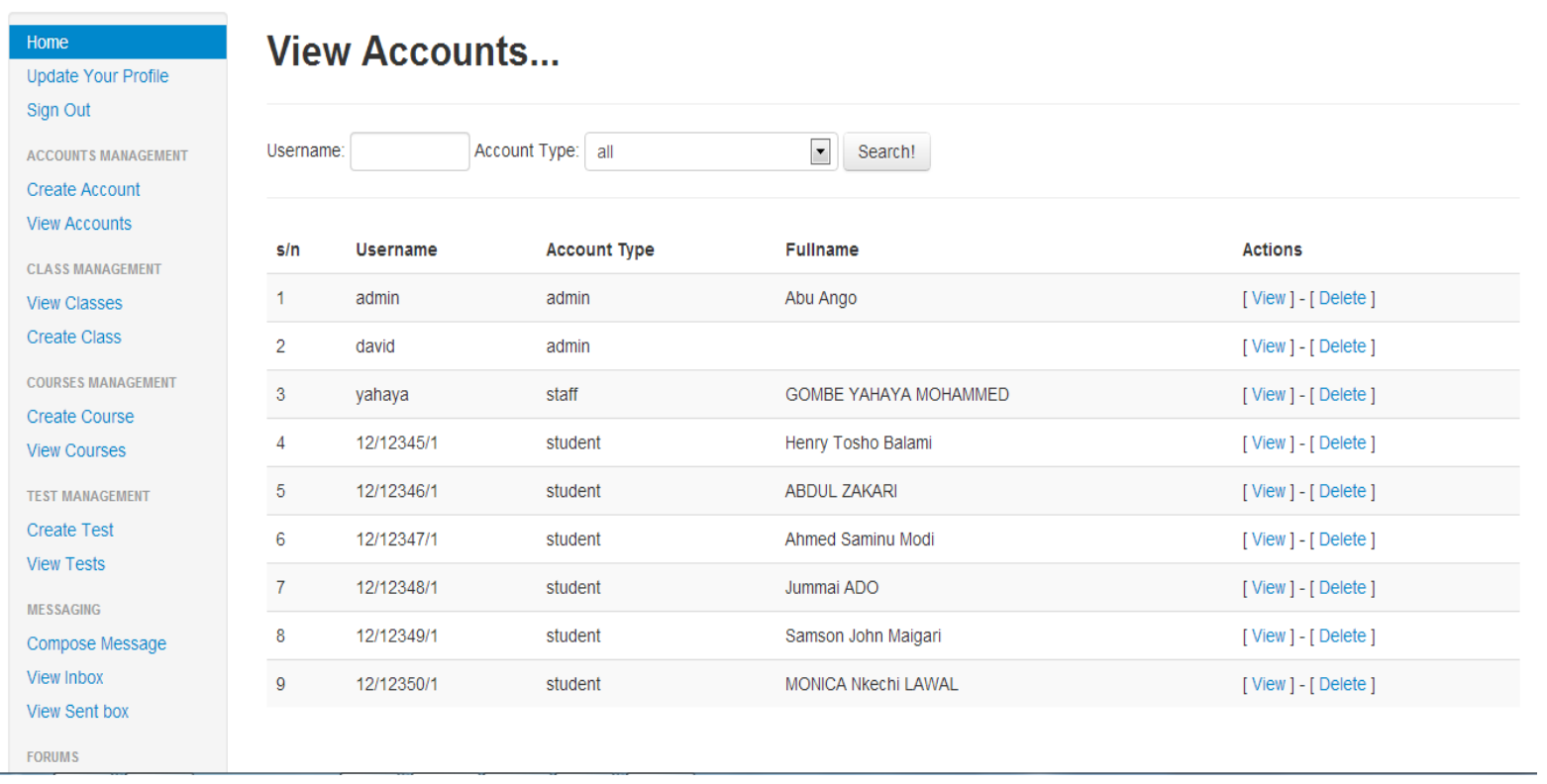

Figure 2A. View of all created accounts. 


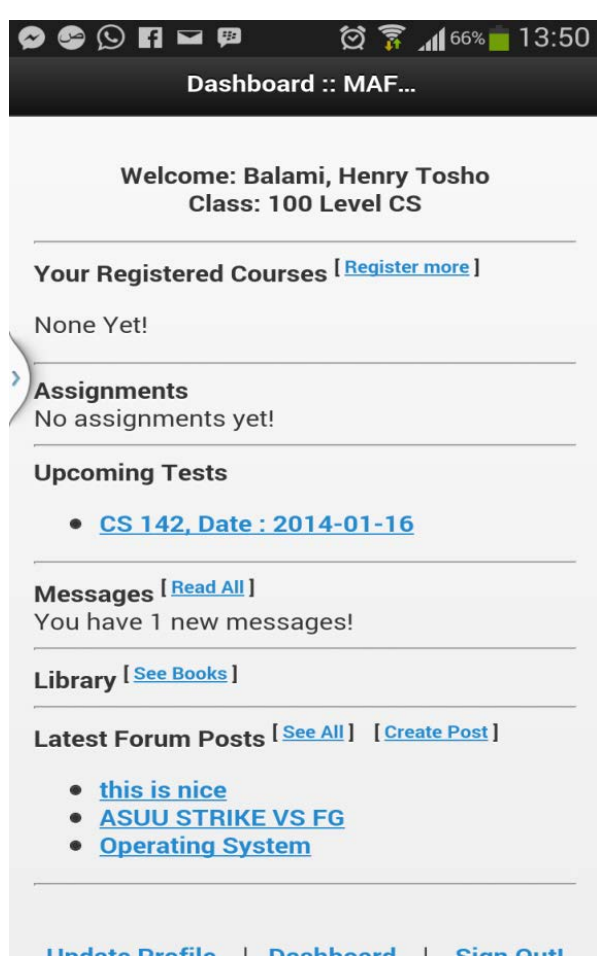

Figure 3A. Students dashboard in SAMSUNG GALAXY S3 with ANDROID OS.

\section{WViéw Post :: MAFHIL}

mafhil.abuango.net/ Google

View Post : MAFHIL

[ See All ] ] [ Create Post ]

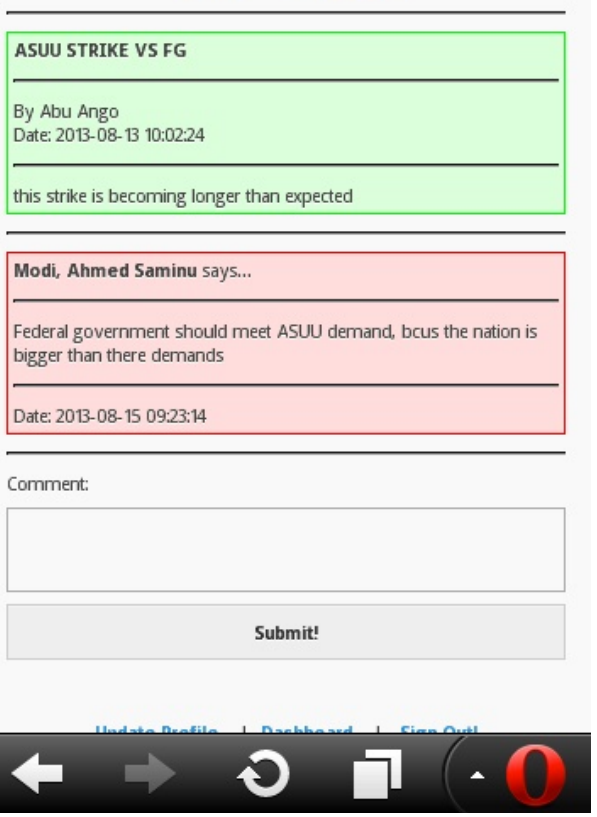

Figure 4A. Viewing comments to a posting. 
VForum Posts :: MAFHIL

mafhil.abuango.net/ $\star$ Google

Forum Posts : MAFHIL

[ See All ] I [ Create Post ]

\begin{tabular}{|l|}
\hline this is nice \\
\hline By Abu Ango \\
Date: 2013-07-23 01:54:42 \\
\hline ASUU STRIKE VS FG \\
\hline By Abu Ango \\
Date: 2013-08-13 10:02:24 \\
\hline Operating System \\
\hline By Modi, Ahmed Sarninu \\
Date: 2013-08-15 09:18:17 \\
\hline Update Profile | Dashboard | Sign Out! \\
\hline
\end{tabular}

○ 2013

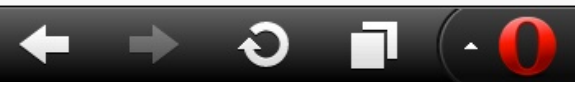

Figure 5A. All posting view.

\begin{tabular}{l}
\hline Library :: MAFHIL \\
\hline Artifi \\
\hline Material on Artificial Intelligence \\
\hline ISBN: Download book \\
\hline DIGITA \\
\hline Basic Digital Building Blocks \\
\hline ISBN: Download book \\
\hline Memory \\
\hline Memory Management \\
\hline ISBN: Download book \\
\hline OS \\
\hline \hline
\end{tabular}

Figure 6A. View of all course materials uploaded. 


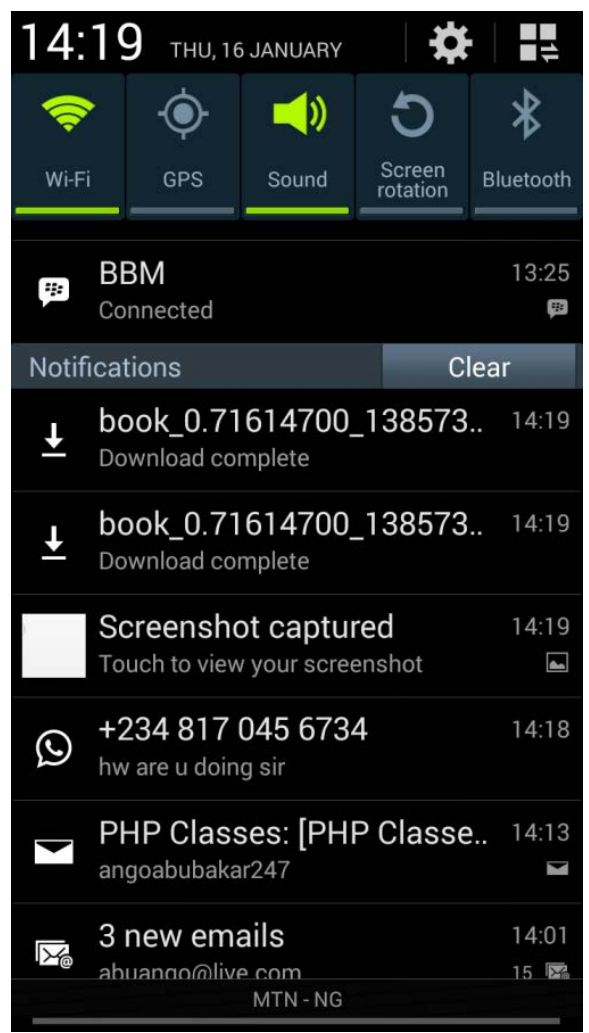

Figure 7A. Course materials downloaded.

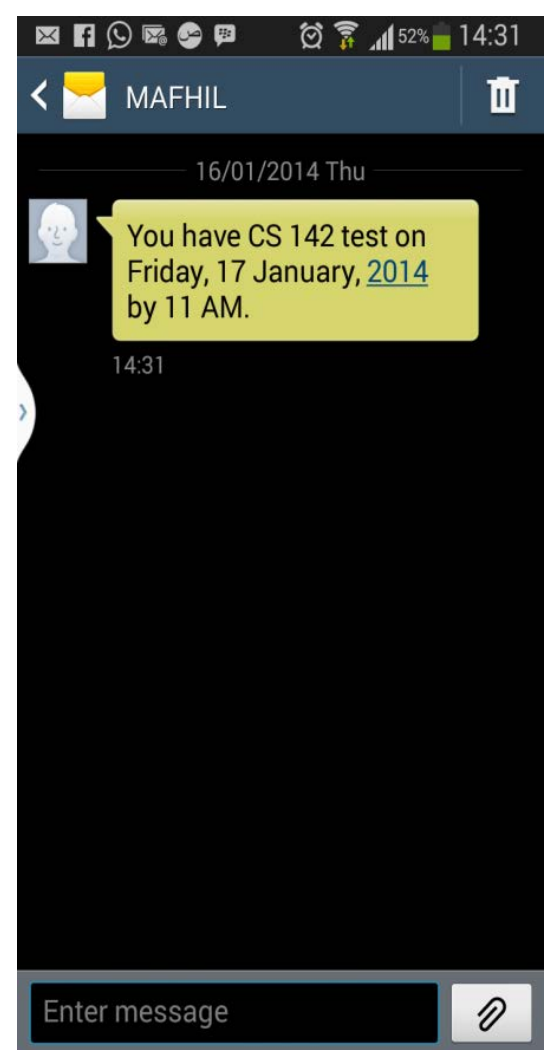

Figure 8A. Received SMS. 


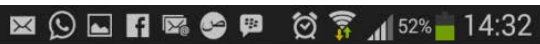
Inbox :: MAFHIL

Compose $\mid$ Inbox $\mid$ Sent

FROM: ANIOBI DAVID EMMANUEL

Date: 2013-11-29 05:31:27

Lecture

Update Profile | Dashboard | Sign Out!

두 2014

Figure 9A. Received message inbox.

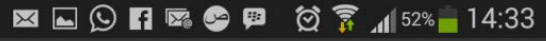
View Message :: ...

Compose | Inbox | Sent

FROM: ANIOBI DAVID EMMANUEL

On: 2013-11-29 05:31:27

Lecture

Message:

There will be CS 142 Lecture on Friday by

4:00pm

Delete | Mark as unread!

Update Profile | Dashboard | Sign Out!

() 2014

Figure 10A. Viewing received message. 
$\leftarrow \rightarrow$ C $\square$ mafhil.abuango.net/admin/testfuncs.php?action=viewall\&id=11

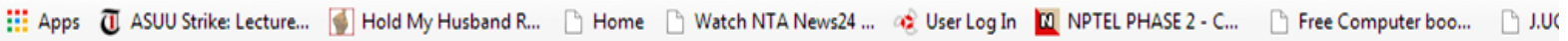
MAFHIL

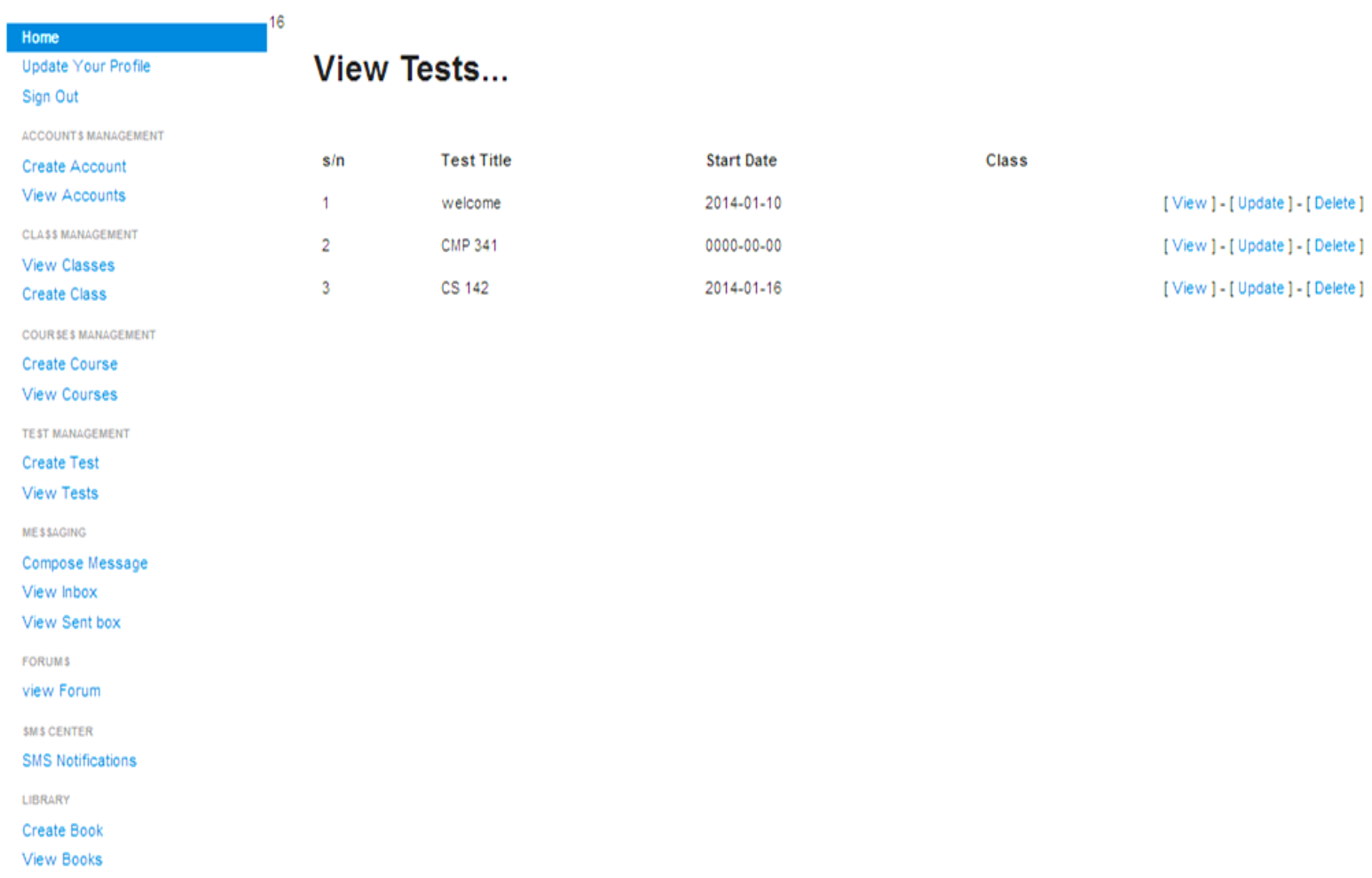

Figure 11A. Viewing created test.

$\leftarrow \rightarrow$ C 17 mafhil.abuangonet/admintestfuncsphp?action=viewBid $=11$

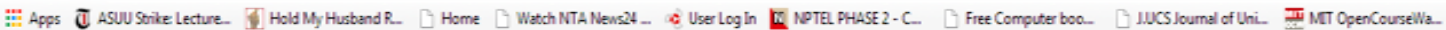

MAFHIL L Logged in as danid

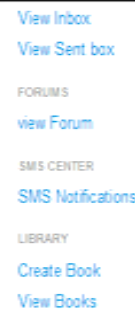

\section{Test Questions [Add Questions}

s/n Question

1 The followings are process scheduing queues Job queve excest

\section{B}

CPU queva

How many transitions are found in the five state 5 model of a process

3 JoyStick is an exampla of dence

4 All of these are types of Read Only Memory PRO (ROM) excest.

5 Which of the following is not a computer JALA programming language

6 Basic unts of computer system are

7 Operating system is a sotuare.

8 All are types of Operating system except

9. Al are operations that can be peformed on a fle Rename excest.

10 The following are types of operating systems personal computer strategies except

(2)

output inpu

ROM

JAVA

hout-outputprocessing-storage application

Mcrosot Suite

Figure 12A. View of created test questions. 


\section{Test Scores}

$$
\begin{array}{|l|}
\hline \text { Student } \\
\hline 12 / 12345 / 1 \\
\hline 12 / 12347 / 1 \\
\hline 12 / 12350 / 1 \\
\hline 12 / 12346 / 1 \\
\hline
\end{array}
$$

\begin{tabular}{|l|}
\hline Date/Time \\
\hline 2014-01-16 05:02:29 \\
\hline 2014-01-16 05:03:21 \\
\hline 2014-01-16 05:05:59 \\
\hline 2014-01-16 05:07:54 \\
\hline
\end{tabular}

Score

4

8

5

10

Q 6.

Figure 13A. Report of test scores.

Welcome to MAFHIL :: Index Page EDGE P.nll
Welcome to MAF...

You are welcome to MAFHIL - Academic Solution

Please Login...

User ID.

Figure 14A. Login screen in BlackBerry with BlackBerry OS.

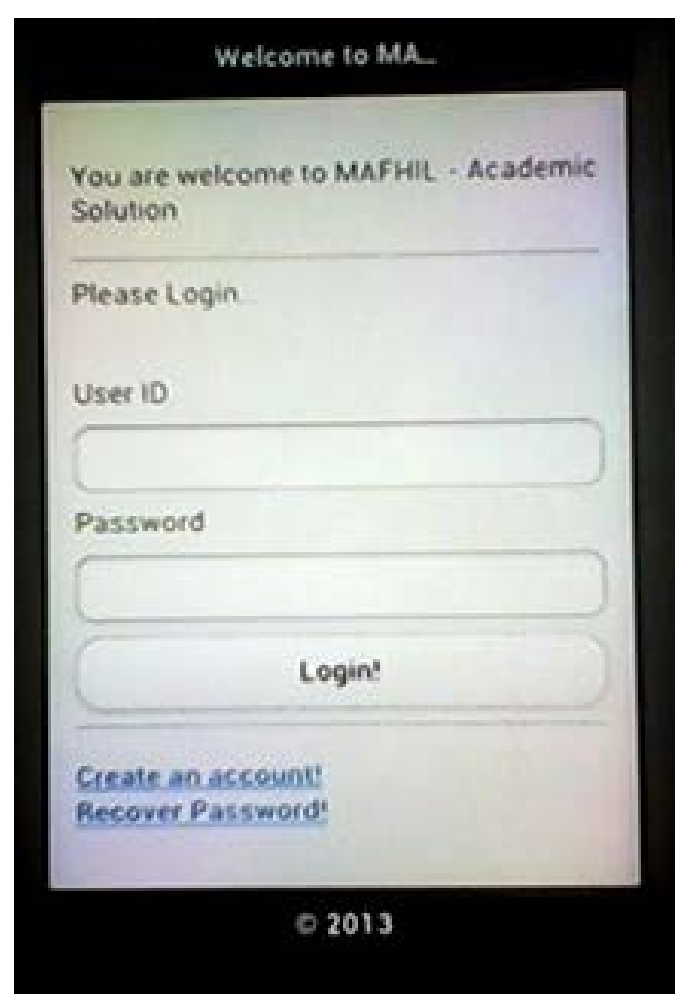

Figure 15A. Login screen in SAMSUNG GALAXY S2 DUOS with Android OS. 


\section{Welcome to..}

You are welcome to MAFHIL -

Academic Solution

Please Login...

User ID.

$12 / 12347 / 1$

Password

*okkkㅏ

Login!

Figure 16A. Login screen in Nokia C7 with Symbian OS \& Opera Mini web browser. 
Scientific Research Publishing (SCIRP) is one of the largest Open Access journal publishers. It is currently publishing more than 200 open access, online, peer-reviewed journals covering a wide range of academic disciplines. SCIRP serves the worldwide academic communities and contributes to the progress and application of science with its publication.

Other selected journals from SCIRP are listed as below. Submit your manuscript to us via either submit@scirp.org or Online Submission Portal.
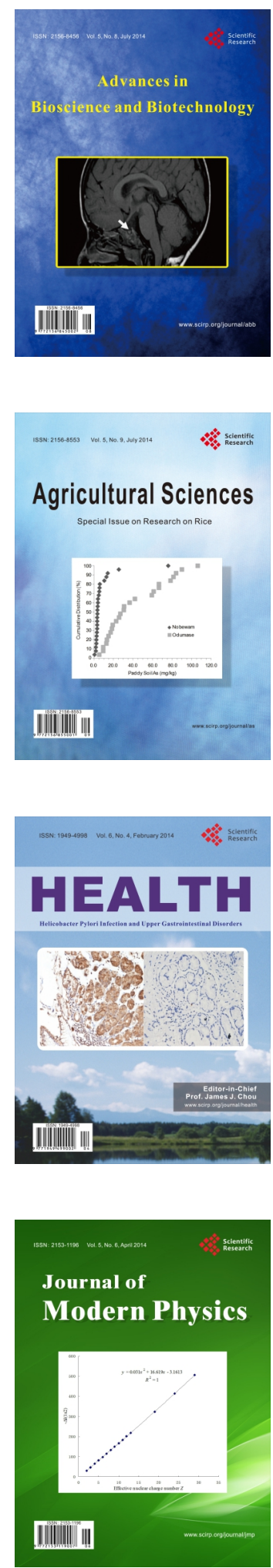
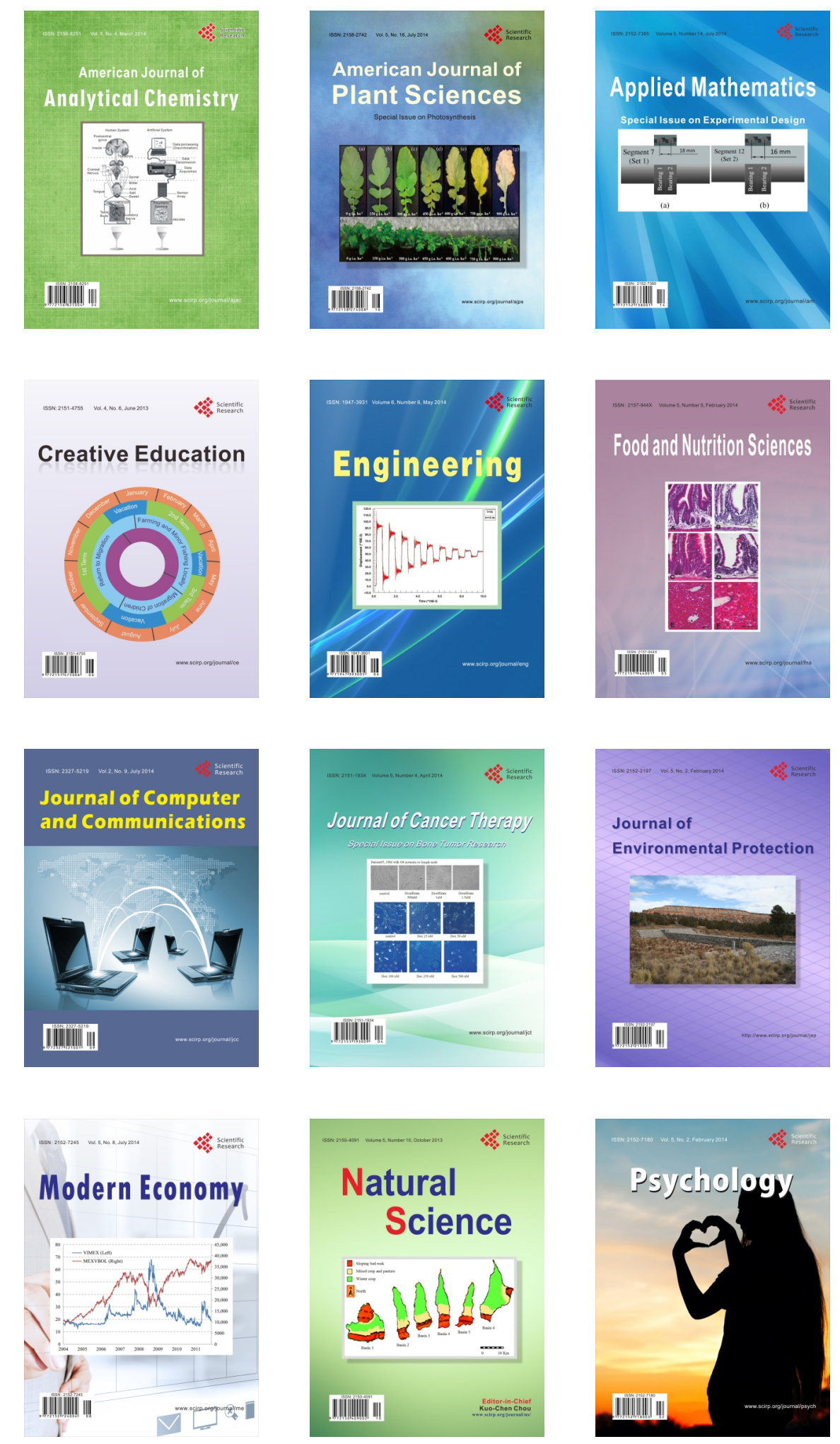